\title{
HUBUNGAN ANTARA ADIKSI GAME TERHADAP KEAKTIFAN PEMBELAJARAN ANAK USIA 9-11 TAHUN
}

\author{
Anastasya Latubessy \\ Fakultas Teknik, Program Studi Teknik Informatika \\ Universitas Muria Kudus \\ Email: anastasya.latubessy@umk.ac.id \\ Muhammad Noor Ahsin \\ Fakultas Keguruan Ilmu Pengetahuan, Program Studi PGSD \\ Universitas Muria Kudus \\ Email: noor.ahsin@umk.ac.id
}

\begin{abstract}
ABSTRAK
Berdasarkan teori kognitif, usia anak 9-11 tahun termasuk dalam kategori yang sudah mampu meningkatkan pemikiran simbolis dan melampaui hubungan informasi sensoris dan tindakan fisik. Oleh sebab itu, pada usia tersebut diperlukan perhatian dan pengawan khusus dalam perkembangan anak. Saat ini, anak berada pada era teknologi digital. Dimana, akses teknologi diperoleh dengan mudah. Anak-anak senang bermain game online dengan perangkat teknologi smartphone dimiliki. Kecenderungan anak dalam bermain ini dapat mengakibatkan pada adiksi game. Sementara tipe game sendiri belum banyak menyediakan game edukasi yang digemari anak. Penelitian ini dilakukan untuk melihat adanya hubungan antara adiksi game dengan keaktifan pembelajaran anak. Aspek keaktifan siswa dalam proses pembelajaran yang digunakan pada penelitian ini meliput aspek visual activities, listening activities, writing activities, motor activities, emotional activities. Menggunakan pendekatan penelitian kualitatif dengan desain penelitian korelasi bivariat. Metode analisis uji korelasi menggunakan Pearson Product Moment dengan bantuan SPSS. Penelitian menyimpulkan bahwa bahwa terdapat hubungan antara adiksi game dengan keaktifan siswa dalam proses pembelajaran. Hubungan yang terjadi adalah korelasi negatif dimana, semakin tinggi adiksi game maka keaktifan siswa dalam proses pembelajaran semakin menurun. Dengan koefisien korelasi antara adiksi game dengan keaktifan siswa dalam proses pembelajaran sebesar $-0,413$ dengan sig. $=0,023$ $(\mathrm{p}<0,05)$.
\end{abstract}

Kata kunci: korelasi, adiksi, game, keaktifan, pembelajaran, anak.

\section{ABSTRACT}

Based on cognitive theory, children ages 9-11 years are included in the category that has been able to improve the relationship beyond the symbolic thought and sensory information and physical action. Therefore, at that age need special attention and oversight in child development. At present, children are in the era of digital technology. Where, access to technology is obtained easily. Children love to play games online with smartphone technology devices owned. The tendency of children in this play could result in addiction game. While this type of game itself has a lot to provide educational game that favored children. This study was conducted to see the connection between addiction game with the liveliness of a child's learning. Aspects of activity of students in the learning process used in this study covered aspects of visual activities, listening activities, writing activities, the motor activities, emotional activities. Using a qualitative approach to research design bivariate correlations. Methods of test analysis using Pearson Product Moment Correlation with SPSS. The study concluded that there is a relationship between gaming addiction with active students in the learning process. The relationship is where the negative correlation, the higher the addiction game then active students in the learning process decreases. With the correlation coefficient between gaming addiction with active students in the learning process of -0.413 with sig. = $0.023(\mathrm{p}<0.05)$.

Keywords: correlation, addiction, game, active, learning, child.

\section{PENDAHULUAN}

Berdasarkan Teori Kognitif, menurut Jean Piaget dalam Santrock, anak umur 7-11 mulai menjelaskan dunia dengan kata-kata dan gambar, ini mencerminkan meningkatkan pemikiran simbolis dan melampaui hubungan informasi sensoris dan tindakan fisik[1].Sehingga pada usia-usia tersebut anak perlu mendapatkan perhatian khusus, dalam memantau perkembangan anak. Era modern saat ini, seiring dengan perkembangan dunia teknologi, 
pengembang game mengembangkan game-game yang menarik minat anak. Maraknya game yang tidak mengandung nilai edukasi, sangat digemari anak-anak saat ini.

Pengertian game adalah aktivitas yang dilakukan untuk fun atau menyenangkan yang memiliki aturan sehingga ada yang menang dan ada yang kalah [2]. Selain itu, game membawa arti sebuah kontes, fisik atau mental, menurut aturan tertentu, untuk hiburan, rekreasi, atau untuk menang taruhan. Menurut Eddy Liem, Direktur Indonesia Gamer yang merupakan sebuah pencinta games di Indonesia, game online adalah sebuah game atau permainan yang dimainkan secara online via internet, bisa menggunakan PC (personal computer) atau konsul game biasa seperti PS2 X-Box dan sejenisnya.

Beberapa penelitian terdahulu seperti penelitian Yahya, M pada tahun 2013 yang berjudul Pengaruh Game Online Terhadap Prestasi Belajar Siswa. Penelitian ini dilakukan dengan menggunakan metode kualitatif, pemilihan informan, orang-orang di ambil berdasarkan kriteria yang telah ditentukan sendiri oleh peneliti sesuai dengan latar dan tujuan dalam penelitian, adapun informan dalam penelitian tersebut adalah pemain game online, orang tua informan, dan juga pemilik game online tersebut. Dari hasil penelitian yang ditemukan faktor-faktor penyebab game online lebih disukai adalah game online lebih menarik daripada pelajaran disekolah, pengaruhnya bagi prestasi remaja tersebut yaitu menurunya prestasi belajar remaja, dan cara mengatasi kecanduan game online yaitu didikan orang tua sangat diperlukan terutama dalam masalah belajar, remaja lebih ditekankan untuk belajar dari pada bermain game online, pemberian motivasi belajar bagi remaja [3].

Selain itu, Harsono, M., pada tahun 2014 dalam penelitiannya yang berjudul Pengaruh Bermain Game terhadap Perkembangan Remaja. Menyimpulkan bahwa salah satu dampak positif dari bermain game adalah sebagai sarana belajar, game membuat anak pandai berbahasa inggris, menumbuhkan sikap pantang menyerah, memudahkan untuk menyelesaikan masalah, menumbuhkan rasa ingin tahu, menambah wawasan, belajar berimajinasi, lebih ambisius, mendapat uang dari game [4].

Tingkatan kelas di sekolah dasar dapat dibagi dua menjadi kelas rendah dan kelas atas. Kelas rendah terdiri dari kelas satu, dua, dan tiga, sedangkan kelas-kelas tinggi sekolah dasar yang terdiri dari kelas empat, lima, dan enam [5]. Di Indonesia, kisaran usia sekolah dasar berada di antara 6 atau 7 tahun sampai 12 tahun. Usia siswa pada kelompok kelas atas sekitar 9 atau 10 tahun sampai 12 tahun. Menurut Piaget dalam Santrock (1986) membagi perkembangan intelektual anak ke dalam 4 periode utama yang berkorelasi dengan dan semakin canggih seiring pertambahan usia: Periode sensori motor (usia 0-2 tahun), Periode praoperasional (usia 2-7 tahun), Periode operasional konkrit (usia 7-11 tahun), Periode operasional formal (usia 11 tahun sampai dewasa). Tahapan operasional konkrit, Tahapan ini adalah tahapan ketiga dari empat tahapan. Muncul antara usia tujuh sampai sebelas tahun dan mempunyai ciri berupa penggunaan logika yang memadai [6].

Oleh sebab itu, untuk menyeimbangkan penggunaan game dengan pembelajaran anak maka diperlukan referensi yang tepat untuk mengembangkan game edukasi yang sesuai dengan kegemaran anak. Penelitian ini melihat hubungan antara adiksi game pada anak usia 9 sampai dengan 11 tahun terhadap keaktifan dalam proses pembelajaran.

\section{METODOLOGI PENELITIAN}

Jenis penelitian yang dilakukan adalah korelasional. Dimana melihat hubungan antara adiksi game dengan keaktifan dalam pembelajaran anak usia 9-11 tahun. Menggunakan pendekatan penelitian kuantitatif dengan desain penelitian menggunakan rancangan penelitian korelasi bivariat. Adapun teknik kampling yang digunakan dalam penelitian ini adalah Sampling Acak Sederhana (Simple Random Sampling). Instrumen yang digunakan adalah angket dengan dua skala penilaian yaitu, Skala Aspek Adiksi dan Skala Keaktifan Siswa dalam Proses Pembelajaran (aspek visual activities, listening activities, writing activities, motor activities, emotional activities).

Metode pengumpulan dan pengolahan data menggunakan proses pengumpulan data self report dimana responden mengisi sendiri jawaban yang dirasa responden paling sesuai dengan dirinya pada angket yang diberikan. Dimana terdapat dua jenis angket, angket yang pertama berisi kumpulan pernyataan yang berhubungan dnegan adiksi game, angket yang kedua berhubungan dengan keaktifan siswa dalam proses pembelajaran. Responden juga diminta untuk mengisi identitas diri yang meliputi nama, usia, tempat tanggal lahir dan jenis kelamin. Setelah itu peneliti menjelaskan terlebih dahulu tentang maksud tujuan dilakukan pengisian angket serta prosedur pengisian angket. Responden diberi waktu 15 menit untuk mengisi angket dan diberikan kesempatan untuk bertanya kepada peneliti maupun mentor yang ikut mendampingi saat itu, apabila mengalami kesulitan dalam pengisian angket. Sementara metode pengolahan data dilakukan analisa dan konstruksi data secara kuantitatif.

Model Pengujian Data menggunakan Tabulasi Mekanis, dimana kegiatan yang dilakukan dalam tabulasi adalah menyusun, menghitung data hasil pengkodean angket, dan kemudian disajikan kedalam tabel korelasi. Menggunakan SPSS yang merupakan tools atau alat bantu hitung. Metode Analisis data metode analisis uji korelasi menggunakan Pearson Product Moment dengan bantuan SPSS. 


\section{HASIL DAN PEMBAHASAN}

Proses analisis dilakukan dengan melihat dua aspek yang dinilai dalam angket yaitu, aspek adiksi dan aspek keaktifan pembelajaran. Sehingga dilakukan perbandingan antara hasil pengujian kedua angket tersebut.

\subsection{Aspek Keaktifan Pembelajaran}

Pengujian pertama dengan 30 responden dari sepuluh pernyataan pada angket keaktifan pembelajaran. Terdapat satu item yang gugur. Hasil pengujian pertama ditunjukan pada Tabel 1, Tabel 2 dan Tabel 3.

Tabel 1. Hasil case processing summary

\begin{tabular}{llcc}
\hline & & $\boldsymbol{N}$ & $\boldsymbol{\%}$ \\
\hline Cases & Valid & 30 & 100.0 \\
& Excluded $^{\mathrm{a}}$ & 0 & .0 \\
& Total & 30 & 100.0
\end{tabular}

a. Listwise deletion based on all variables in the procedure.

Tabel 2. Hasil reliability statistics

\begin{tabular}{cc}
\hline Cronbach's Alpha & Nof Items \\
\hline .791 & 10 \\
\hline
\end{tabular}

Tabel 3. Hasil item-total statistics

\begin{tabular}{|c|c|c|c|c|}
\hline & $\begin{array}{l}\text { Scale Mean } \\
\text { Item Deleted }\end{array}$ & $\begin{array}{l}\text { Scale Variance } \\
\text { Item Deleted }\end{array}$ & $\begin{array}{l}\text { f Corrected Item- } \\
\text { Total Correlation }\end{array}$ & $\begin{array}{l}\text { Cronbach's Alpha if } \\
\text { Item Deleted }\end{array}$ \\
\hline VAR00001 & 13.83 & 16.006 & .573 & .761 \\
\hline VAR00002 & 13.87 & 18.120 & .153 & .808 \\
\hline VAR00003 & 13.93 & 16.685 & .504 & .770 \\
\hline VAR00004 & 13.93 & 16.823 & .424 & .778 \\
\hline VAR00005 & 13.87 & 16.464 & .485 & .771 \\
\hline VAR00006 & 13.93 & 17.651 & .350 & .785 \\
\hline VAR00007 & 13.50 & 14.190 & .588 & .757 \\
\hline VAR00008 & 13.57 & 14.806 & .536 & .764 \\
\hline VAR00009 & 13.23 & 15.151 & .513 & .767 \\
\hline VAR00010 & 14.03 & 16.516 & .578 & .764 \\
\hline
\end{tabular}

Pengujian kedua dengan sembilan item. Item yang gugur pada pengujian pertama dihilangkan. Hasilnya ditunjukan pada Tabel 4, Tabel 5 dan Tabel 6.

Tabel 4. Case processing summary

\begin{tabular}{llll}
\hline & & $\boldsymbol{N}$ & $\boldsymbol{\%}$ \\
\hline Cases & Valid & 30 & 100.0 \\
& Excluded $^{\mathrm{a}}$ & 0 & .0 \\
& Total & 30 & 100.0 \\
\multicolumn{2}{l}{ a. Listwise deletion based on all variables in the procedure. }
\end{tabular}

Tabel 5. Reliability statistics

\begin{tabular}{cc}
\hline Cronbach's Alpha & Nof Items \\
\hline .808 & 9 \\
\hline
\end{tabular}


Tabel 6. Item - total statistics

\begin{tabular}{clccc}
\hline & $\begin{array}{l}\text { Scale Mean } \\
\text { Item Deleted }\end{array}$ & $\begin{array}{c}\text { if Scale Variance if Corrected } \\
\text { Item Deleted }\end{array}$ & $\begin{array}{c}\text { Item- Cronbach's Alpha if } \\
\text { Total Correlation }\end{array}$ \\
Item Deleted
\end{tabular}

\subsection{Aspek Adiksi}

Pengujian pertama dengan 30 responden dari sepuluh pernyataan pada angket aspek adiksi. Juga terdapat satu item yang gugur. Ditunjukan pada Tabel 7, Tabel 8 dan Tabel 9.

Tabel 7. Case processing summary

\begin{tabular}{llll}
\hline & & $\boldsymbol{N}$ & $\mathbf{\%}$ \\
\hline Cases & Valid & 3 & 100.0 \\
& & 0 & \\
& Excluded $^{\mathrm{a}}$ & 0 & .0 \\
& Total & 3 & 100.0
\end{tabular}

a. Listwise deletion based on all variables in the procedure.

Tabel 8. Reliability statistics

\begin{tabular}{cc}
\hline Cronbach's Alpha & Nof Items \\
\hline .843 & 10 \\
\hline
\end{tabular}

Tabel 9. Item - total statistics

\begin{tabular}{ccccc}
\hline & $\begin{array}{c}\text { Scale } \\
\text { Item Deleted }\end{array}$ & $\begin{array}{c}\text { Mean } \\
\text { if Scale Variance if Corrected }\end{array}$ & $\begin{array}{c}\text { Item- Cronbach's Alpha if } \\
\text { Item Deled }\end{array}$ & $\begin{array}{c}\text { Total Correlation } \\
\text { Item Deleted }\end{array}$ \\
\hline VAR00001 & 28.57 & 18.185 & .684 & .815 \\
VAR00002 & 28.43 & 18.944 & .586 & .824 \\
VAR00003 & 28.73 & 18.616 & .487 & .834 \\
VAR00004 & 28.70 & 21.734 & .110 & .862 \\
VAR00005 & 28.73 & 19.651 & .530 & .830 \\
VAR00006 & 28.97 & 18.723 & .643 & .819 \\
VAR00009 & 28.87 & 17.637 & .657 & .816 \\
VAR00010 & 29.10 & 17.886 & .611 & .821 \\
VAR00008 & 28.60 & 19.352 & .445 & .837 \\
VAR00007 & 28.70 & 17.941 & .664 & .816 \\
\hline
\end{tabular}

Dilakukan pengujian tahap kedua dengan menggunakan sembilan item. Dengan hasil seperti yang ditunjukan pada Tabel 10, Tabel 11 dan Tabel 12. 
Tabel 10. Case processing summary

\begin{tabular}{llll}
\hline & & $\boldsymbol{N}$ & \% \\
\hline Cases & Valid & 30 & 100.0 \\
& Excluded $^{\mathrm{a}}$ & 0 & .0 \\
& Total & 30 & 100.0
\end{tabular}

a. Listwise deletion based on all variables in the procedure.

Tabel 11. Reliability statistics

\begin{tabular}{cc}
\hline Cronbach's Alpha & Nof Items \\
\hline .862 & 9 \\
\hline
\end{tabular}

Tabel 12. Item - total statistics

\begin{tabular}{ccccc}
\hline & \multicolumn{2}{c}{$\begin{array}{c}\text { Scale Mean if Item Scale Variance } \\
\text { Deleted }\end{array}$} & $\begin{array}{c}\text { if Corrected } \\
\text { Item Deleted }\end{array}$ & $\begin{array}{c}\text { Item- Cronbach's Alpha if } \\
\text { Total Correlation }\end{array}$ \\
\hline Item Deleted
\end{tabular}

Dari hasil uji linearitas diperoleh nilai $F_{\text {beda }}$ sebesar 0, 644 dengan sig.= 0,777 (p>0,05) yang menunjukkan hubungan antara adiksi game dengan keaktifan pembelajaran adalah linear, ditunjukan pada Tabel 13.

Tabel 13. Tabel anova

\begin{tabular}{|c|c|c|c|c|c|c|c|}
\hline & & & Sum of Squares & $d f$ & Mean Square & $F$ & Sig. \\
\hline \multirow{5}{*}{$\begin{array}{l}\text { Pembelajaran } \\
\text { * Adiksi }\end{array}$} & \multirow{3}{*}{$\begin{array}{l}\text { Between } \\
\text { Groups }\end{array}$} & (Combined) & 231.700 & 13 & 17.823 & .971 & .515 \\
\hline & & Linearity & 89.760 & 1 & 89.760 & 4.889 & .042 \\
\hline & & $\begin{array}{l}\text { Deviation from } \\
\text { Linearity }\end{array}$ & 141.940 & 12 & 11.828 & .644 & .777 \\
\hline & \multicolumn{2}{|c|}{ Within Groups } & 293.767 & 16 & 18.360 & & \\
\hline & \multicolumn{2}{|c|}{ Total } & 525.467 & 29 & & & \\
\hline
\end{tabular}

Tabel 14. One sample kolmogorov smirnov test

\begin{tabular}{llcc}
\hline & & Pembelajaran & Adiksi \\
\hline \multicolumn{1}{c}{ N } & & 30 & 30 \\
Normal Parameters & Mean & 13.87 & 29.30 \\
& Std. Deviation & 4.257 & 3.897 \\
Most Extreme Differences & Absolute & .203 & .105 \\
& Positive & .203 & .089 \\
& Negative & -.134 & -105 \\
Kolmogorov-Smirnov Z & & 1.111 & .573 \\
Asymp. Sig. (2-tailed) & & .169 & .898 \\
a. Test distribution is Normal. & & & \\
\hline
\end{tabular}


Berdasarkan uji hasil pengujian normalitas pada Tabel 14, kedua variabel memiliki signifikansi p>0,05. Variabel adiksi game memiliki nilai K-S-Z sebesar 1.,111 dengan probabilitas (p) atau signifikansi sebesar 0,169 $(\mathrm{p}>0,05)$. Oleh karena nilai signifikansi $\mathrm{p}>0,05$, maka distribusi data adiksi game berdistribusi normal. Hal ini juga terjadi pada variabel keaktifan pembelajaran yang memiliki nilai K-S-Z sebesar 0,573 dengan probabilitas (p) atau signifikansi sebesar 0,898. Sementara hasil perhitungan statistik untuk skala pembelajaran dan adiksi ditunjukan pada Tabel 15 .

Tabel 15. Descriptive statistics

\begin{tabular}{lccccc}
\hline & $\boldsymbol{N}$ & Minimum & Maximum & Mean & Std. Deviation \\
\hline Pembelajaran & 30 & 9 & 23 & 13.87 & 4.257 \\
Adiksi & 30 & 20 & 36 & 29.30 & 3.897 \\
Valid N (listwise) & 30 & & & & \\
\hline
\end{tabular}

Tabel 16. Hasil uji korelasi

\begin{tabular}{llcc}
\hline & & Pembelajaran & Adiksi \\
\hline Pembelajaran & Pearson Correlation & 1 & $-.413^{*}$ \\
& Sig. (2-tailed) & & .023 \\
& $\mathrm{~N}$ & 30 & 30 \\
Adiksi & Pearson Correlation & $-.413^{*}$ & 1 \\
& Sig. (2-tailed) & .023 & \\
& $\mathrm{~N}$ & 30 & 30 \\
*. Correlation is significant at the 0.05 level (2-tailed). & \\
\hline
\end{tabular}

Berdasarkan hasil perhitungan uji korelasi yang ditunjukan pada Tabel 16, diperoleh koefisien korelasi antara adiksi game dengan keaktifan siswa dalam proses pembelajaran sebesar 0,413 dengan sig. $=0,023(\mathrm{p}<0,05)$ yang berarti ada korelasi antara adiksi game dengan keaktifan siswa dalam proses pembelajaran. Tanda negatif menunjukan korelasi yang terbentuk adalah korelasi negatif yang artinya, semakin tinggi adiksi game maka keaktifan siswa dalam proses pembelajaran semakin menurun.

\section{KESIMPULAN}

Beberapa hal yang disimpulkan sebagai hasil penelitian adalah :

1) Berdasarkan hasil penelitian maka disimpulkan bahwa terdapat hubungan antara adiksi game dengan keaktifan siswa dalam proses pembelajaran. Hubungan yang terjadi adalah korelasi negative dimana, semakin tinggi adiksi game maka keaktifan siswa dalam proses pembelajaran semakin menurun. Dengan koefisien korelasi antara adiksi game dengan keaktifan siswa dalam proses pembelajaran sebesar -0,413 dengan sig. $=0,023(\mathrm{p}<0,05)$.

2) Perlu adanya kepedulian baik dari orang tua sebagai pendidik pertama dalam proses tumbuh kembang anak.

3) Perlu adanya kepedulian dari pengembang software game agar dapat mengembangkan software game yang bersifat edukasi namun tidak mengurangi unsur fun/kesenangan dalam bermain game, sehingga anak dapat berlama-lama bermain game edukasi tersebut.

\section{DAFTAR PUSTAKA}

[1] Santrock, J.W., 2007, Perkembangan Anak Jilid 1 Edisi 11, Penerbit Erlangga, Jakarta.

[2] http://www.macmillandictionary.com/, Diakses tanggal 22 Maret 2016.

[3] Yahya, M., 2013, Pengaruh Game Online Terhadap Prestasi Belajar Siswa, Jurnal Ilmiah, Fakultas Ilmu Pendidikan, Universitas Negeri Semarang.

[4] Harsono, M, 2014, Pengaruh Bermain Game terhadap Perkembangan Remaja, Surya University, Serpong.

[5] Supandi, 1992:44, Karakteristik Siswa Sekolah Dasar, Direktori File UPI, Bandung.

[6] Santrock, J.W., 1986, Life-span development (Perkembangan Masa Hidup), Penerbit Erlangga, Jakarta 